\title{
A ANALOGIA DA RELIGIÃO (INTRODUÇÃO) ${ }^{1}$
}

\author{
Joseph Butler \\ Tradução por Bruna Frascolla Bloise ${ }^{2}$
}

\section{Um retrato filosófico da época: breve introdução ao texto traduzido}

Um retrato do ambiente filosófico da época de David Hume é o que temos no intento da Analogia da religião, do bispo Joseph Butler: um discurso que se pretende experimental e que vê na filosofia natural um novo meio de fundamentar o monoteísmo. Não é difícil apontar qual seja a grande filosofia inspiradora e modelo desse discurso.

Trata-se de Newton. Por um lado ele era o autor do mote Hypotheses non fingo, que condena a teoria que não se baseie em experimentos; por outro, era o filósofo eminentemente natural que tivera sucesso retumbante em sua área e atestava, portanto com toda a autoridade, que Deus existia. "O olho", dizia Newton, "foi engendrado sem habilidades em ótica, e o ouvido sem conhecimento dos sons?" (NEWTON, 2003, p. 369-70). Subentendendo-se resposta negativa, havemos de reconhecer que há um criador versado em física, que fez um mundo cujas leis Newton desvendara.

A recusa de hipóteses metafísicas e a afirmação da existência de um criador inteligente andavam juntas na filosofia de Newton. Acontece que ele tinha de se defender da acusação leibniziana de que, como não postulava causas, sua física era uma mera indução não explicativa, que nela apenas se descreviam leis segundo as quais os fenômenos têm se comportado e no entanto não sabíamos por que eles se comportavam de tal modo. A defesa de Newton é remeter a Deus a explicação para os fenômenos: "devem as Leis constantes e universais da Natureza, se derivadas do poder de Deus ou da ação duma causa ainda desconhecida para nós, ser chamadas de milagres ou qualidades ocultas?, isto é dizer maravilhas e absurdidades?" (NEWTON, 1715, p. 224) Ter-se-á, pois, postulada uma causa, e o que a física newtoniana fará é desvelar as leis com as quais o criador onisciente e onipotente rege o mundo. $\mathrm{Ou}$, em suas próprias palavras, Newton "ensina que filósofos devem argumentar a partir de fenômenos e experimentos até as suas causas, e então às causas dessas causas, e assim por diante até chegarmos à primeira Causa" (Idem). Ora, uma vez que as causas só podem ser descobertas via observação de fenômenos e Deus é uma causa, então temos que poder descobri-lo a partir do mundo.

\footnotetext{
${ }^{1}$ Tradução da introdução da obra de Joseph Butler: The Analogy of Religion Natural and Revealed to the Constitution and Course of Nature. Londres : Chiswick Press, 1857, p. 1-14

${ }^{2}$ Mestranda pelo Programa de Pós-Graduação em Filosofia da Universidade Federal da Bahia. E-mail: brunafrascolla@gmail.com.
} 
Newton, então, deixou em aberto uma missão a ser cumprida por teólogos, e a estes, que vivenciavam o calor do triunfo da física newtoniana sobre a cartesiana e a aristotélico-ptolomaica, não poderia faltar entusiasmo para cumpri-la. Como as físicas rechaçadas tinham um grande respaldo em raciocínios filosóficos apriorísticos, os teólogos traduziram o Hipotheses non fingo numa recusa do pensamento metafísico e na afirmação de que toda teoria tem que ter algum respaldo em fatos empíricos. A teologia destinada a cumprir a missão deixada por Newton será o chamado teísmo experimental ou religião natural, que se baseia no que hoje chamamos de argumento do desígnio - aquele que afirma a existência de um criador perfeito com base na perfeição do mundo. O nome de "religião natural" advém da suposta inerência da crença em Deus, que só poderia ser negada pela teimosia dos ímpios através dos raciocínios mais abstrusos. Tudo o que o teísta haveria de fazer para refutá-los é meramente apontar a perfeição do mundo para que sigamos nossa inclinação natural de lhe atribuir um criador inteligente. O nome de "teísmo experimental", por sua vez, vem deste gesto de apontar o mundo: Como a retórica newtoniana se contrapunha à metafísica que argumentava a priori acerca do mundo e de Deus, a mera menção às características do mundo já bastava para que teólogos se considerassem experimentais.

Pois bem: enfatizamos que há de haver algum respaldo empírico porque, como se verá abaixo no texto de Butler, é fácil apontar a total ausência de rigor científico em seu projeto de afirmar a semelhança entre a Bíblia e as leis da natureza, e assim inferir que ambas provêm do mesmo autor. Trata-se, como indica o título do livro, duma analogia, ou, mais ainda, dalgo feito por raciocínio analógico. Assim, antes de fundamentar a cristandade sobre tal raciocínio, nesta introdução Butler se dedica a legitimar seu expediente afirmando a absoluta necessidade que os humanos têm de raciocinar com base em analogia em todas as questões factuais (i. e., as questões que não têm necessidade, como as matemáticas têm) com as quais se depare na vida. Como sabemos, por exemplo, que o sol nascerá amanhã? Ora, vimo-lo nascer desde que nos entendemos por gente, e todos nos garantem que sempre foi assim. E hoje se assemelha a ontem, anteontem, etc.; portanto, de modo semelhante, o sol nascerá amanhã. Se este raciocínio analógico, dirá Butler, é humanamente forçoso para que saibamos qualquer coisa do domínio dos fatos, como poderemos nos recusar a aplicá-lo à religião?

Teologia à parte, o leitor humeano achará no texto de Butler perguntas que também foram feitas por Hume nas seções IV e V da Investigação sobre o entendimento humano, e na certa verá como suas respostas, mais do que diferentes, são também uma negativa à filosofia da época. Teologia inclusa achar-se-á aqui o modelo de leitor que Hume esperava ao castrar o seu Tratado da natureza humana cortando-lhe pelo menos uma seção sobre milagres ${ }^{3}$.

\section{Referências bibliográficas:}

\footnotetext{
${ }^{3}$ Hume escreve o seguinte a Henry Home, referindo-se a cortes no Tratado:"Estou atualmente castrando a minha obra, isto é, cortando suas partes nobres, isto é, esforçando-me para que ela cause a menor ofensa possível; antes disso, não posso pretender colocá-la nas mãos de Butler." (HUME, 1969, p. 2, apud MONTEIRO, 2009, p. 159)
} 
MONTEIRO, João Paulo. Hume e a Epistemologia. 1ªed. São Paulo: UNESP, Discurso, 2009.

NEWTON, Isaac. An account of the book entituled Commercium epistolicum collinii et aliorum, de analyse promota. Philosophical Transaction of the Royal Society, Londres, n. 342, p. 173-224, jan./fev., 1715.

. Opticks. Nova Iorque: Prometheus, 2003. 


\section{Tradução \\ A ANALOGIA DA RELIGIÃO (INTRODUÇÃO)}

A evidência provável se distingue essencialmente da demonstrativa porque admite graus, e de toda variedade: da mais elevada certeza moral à mais baixa presunção. De fato, não podemos dizer que uma coisa é provavelmente verdadeira nos baseando numa presunção bem frágil, porque como pode haver probabilidades em ambos os lados dum problema, pode haver uma contra; e mesmo que não haja, ainda assim, uma presunção frágil não engendra o grau de convicção que se implica ao dizermos que uma coisa é provavelmente verdadeira. Mas concluímos que a mais frágil presunção é da natureza de uma probabilidade porque tal presunção baixa, se repetida muitas vezes, se tornará até mesmo uma certeza moral. Assim, um homem ter observado apenas hoje a vazante e a cheia da maré fornece alguma sorte de presunção, embora a mais baixa imaginável, de que isso acontecerá novamente amanhã; mas a observação conjunta desse evento (como foi feita pela humanidade) por tantos dias, meses e eras, nos dá uma segurança plena de que isso acontecerá.

Aquilo que de modo principal constitui a probabilidade se expressa pela palavra verossímil [likely], i. e., semelhante [like] a alguma verdade ${ }^{4}$ ou evento verdadeiro; ou semelhante a isto em si próprio, ou em sua evidência, ou em algo a mais ou a menos de circunstâncias. Afinal, quando determinamos que uma coisa é provavelmente verdadeira ou supomos que um evento aconteceu ou acontecerá, é por a mente ter notado nisto uma semelhança com outro evento que observamos ter acontecido. $\mathrm{E}$ essa observação forma, em incontáveis exemplos diários, ou uma presunção, ou uma opinião ou uma convicção plena de que tal evento aconteceu ou acontecerá, se a observação for de que o evento semelhante aconteceu ou algumas vezes, ou muito comumente ou sempre desde o início de nossa observação, em distâncias semelhantes de tempo, de espaço, ou sob condições semelhantes. Disto surge a crença de que uma criança, se viver vinte anos, crescerá para a estatura e força de um homem, que comida contribuirá para a preservação de sua vida, e a falta dela por tal número de dias será sua destruição certa. Assim, de modo semelhante, a regra e medida de nossas esperanças e medos concernentes ao sucesso de nossas metas, as nossas expectativas de que os outros agirão de tal e tal jeito em tais circunstâncias, o nosso juízo de que tais ações procedem de tais princípios - tudo isto depende de termos observado o semelhante seja a respeito dos outros, seja ao nosso próprio respeito. E assim, en-

\footnotetext{
${ }^{4}$ Verisimile. [De acordo com o Oxford Latin Dictionary (Londres: Claredon Press, 1968, p. 1763), “Assemelhado à verdade, provável, razoável, plausúvel”. Escolhemos "verossímil" para traduzir "likely" (e não como "provável", que é o modo mais comum de se traduzir) por Butler acudir a esta etimologia. Já "probabilidade" e "provável" traduzem "probability" e "probable".]
} 
quanto o príncipe ${ }^{5}$ que sempre vivera num clima quente naturalmente concluiu no modo da analogia que não existia uma tal coisa como a água ficar dura porque ele sempre a observara fluida, nós, ao contrário, concluímos por analogia que não há presunção alguma contra isto; que pode-se supor que haverá geada na Inglaterra num determinado dia do próximo janeiro, que é provável que a haverá em algum dia do mês e que há uma certeza moral (i.e., fundamento para uma expectativa sem qualquer dúvida) disto em um momento ou outro do inverno.

Em sua real natureza, a evidência provável fornece apenas um tipo imperfeito de informação e deve ser considerada relativa apenas a seres de capacidades limitadas, pois nada que é objeto de conhecimento possível, seja passado, presente ou futuro, pode ser provável para uma inteligência infinita, uma vez que não pode ser discernida absolutamente em si mesma como certamente verdadeira ou certamente falsa. Mas, para nós, probabilidade é o verdadeiro guia da vida.

Disso se segue que em problemas de dificuldade ou tais que sejam tidos assim, quando não se pode ter ou não se vê uma evidência mais satisfatória, se o resultado do exame for que pelo conjunto surge alguma presunção baixíssima de um lado contra nenhuma do outro, ou uma presunção maior de um lado - embora maior no mais baixo grau -, esta determinará o problema até em questões de especulação, e em questões de prática nos deixará sob uma obrigação absoluta e formal, no que diz respeito a prudência e interesse, de agir com base nessa presunção ou baixa probabilidade, mesmo que seja tão baixa que deixe a mente em grande dúvida de qual seja a verdade. Afinal, decerto os homens são obrigados pela prudência a fazer tanto o que, de acordo com seu melhor juízo, parece pelo conjunto ser bom para a sua felicidade, quanto o que ele sabe sê-lo com certeza. Mais ainda, em problemas de grande consequência, um homem razoável pensará que lhe interessa notar probabilidades e presunções mais baixas do que essas, até que cheguem a não mais do que mostrar que um lado do problema é tão possível de se supor e crível quanto o outro; e mais, até que se tornem muito inferiores a esse lado. Afinal, podem-se mencionar incontáveis exemplos, no que diz respeito às metas comuns da vida, em que se acharia que um homem é distraído (num sentido literal) se não agir, e com grande aplicação também, não apenas com base numa chance grande, mas com base em outras muito menores e onde a probabilidade ou chance fosse enormemente contra seu acontecimento. ${ }^{6}$

Não é meu desígnio investigar com mais profundidade a natureza, a fundação e medida da probabilidade, ou se procede que a semelhança deva engendrar essa presunção, opinião e plena convicção que a mente humana é formada para receber dela e que ela produz necessariamente em cada um, ou prevenir os erros aos quais o raciocínio por analogia é propenso. Isto é assunto da lógica, e é uma parte do assunto que ainda não se considerou perfeitamente. De fato, não devo me incumbir de dizer o quanto a extensão, o limite e a força do raciocínio analógico pode ser reduzido a preceitos e regras gerais, e o conjunto conformado num sistema. Mas, embora tão pouco neste sentido tenha sido tentado pelos que têm tratado dos nossos poderes e exercí-

\footnotetext{
${ }^{5}$ A história é contada pelo Sr. Locke no capítulo Da Probabilidade. [Trata-se do capítulo 15 do livro IV do Ensaio sobre o entendimento humano.]

${ }^{6}$ Cf. Cap. VI, parte II.
} 
cios intelectuais, isto não impede que possamos estar (como inquestionavelmente estamos) seguros de que a analogia tem peso em vários graus para determinarmos nosso juízo e nossa prática. A analogia tampouco cessa de ter peso nesses casos porque alguns (quer os dados à disputa, quer os que requerem que as coisas sejam formuladas com mais exatidão do que as nossas faculdades parecem admitir em questões práticas) podem encontrar outros casos em que não é fácil dizer se ela tem peso ou não, ou exemplos de analogias aparentes que na verdade não são de nenhumas. É suficiente para o presente propósito observar que este modo geral de discutir é evidentemente natural, justo e conclusivo, porquanto nenhum homem pode fazer uma tal pergunta como a de se o sol nascerá amanhã e ser visto onde sempre o fora, na figura de um círculo e não na de um quadrado.

Por conseguinte, a saber, por raciocínio analógico, Orígenes ${ }^{7}$ observou com singular sagacidade que "aquele que crê que a Escritura proveio d'Aquele que é o Autor da Natureza pode bem esperar o mesmo tipo de dificuldade nela [i.e., na Escritura] que os que são encontrados na constituição da natureza." E num tipo semelhante de reflexão, pode-se acrescentar que aquele que nega que a Escritura provenha de Deus por causa dessas dificuldades pode, pela mesmíssima razão, negar que o mundo provenha d'Ele. Por outro lado, se houver uma analogia ou semelhança entre esse sistema de coisas e a dispensação da Providência dos quais a revelação nos informa e o sistema de coisas e dispensação dos quais a experiência junto com a razão nos informa (i. e., o curso conhecido da natureza), isto será uma presunção de que ambos têm o mesmo autor e a mesma causa - aos menos na medida em que responde a objeções contra a natureza advir de Deus, sendo extraída de qualquer coisa que seja análoga ou similar ao que está na Escritura (que é reconhecidamente proveniente d'Ele), visto que um autor da natureza é suposto aqui.

Formar nossas noções da constituição e do governo do mundo com base em raciocínios, sem fundação para os princípios que assumimos, quer dos atributos de Deus, quer de qualquer outra coisa, é construir um mundo sobre hipóteses, como fizera Descartes. Formar nossas ações com base em raciocínio proveniente de princípios que são certos, mas aplicados a casos nos quais não temos nenhum fundamento para aplicá-los (como aqueles que explicam a estrutura do corpo e a natureza de doenças a partir de mera matemática) é um erro muito parecido com o primeiro, porquanto o que se assume a fim de tornar o raciocínio aplicável é hipótese. Mas se concede que é justo aliar raciocínios abstratos a observação de fatos, e argumentar a partir de tais fatos como são conhecidos passando-se a outros que lhe são semelhantes; a partir desta parte do governo divino sobre as criaturas inteligentes que vem às nossas vistas, passando-se ao governo maior e mais geral que está acima deste; e a partir do que está presente para coletar o que é verossímil ou crível para o estado futuro.

Então, sendo prático este método de concluir e determinar, e sendo o caso que, se formos agir, podemos agir apenas sobre as metas comuns da vida, sendo tal método evidente e conclusivo em vários graus, proporcionável ao grau de exatidão

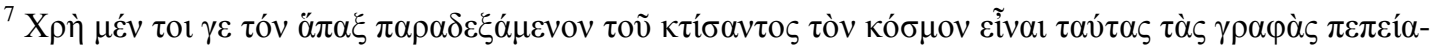

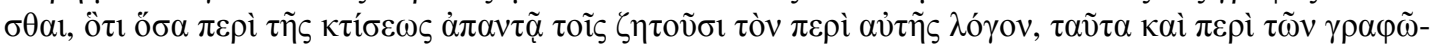
v. Phil. p. 23. ed. Cant. [Esta é a citação que Butler traduz a seguir.]
} 
da grande analogia ou semelhança, e havendo tão grande autoridade para introduzi-lo no assunto da religião, até mesmo no da religião revelada, meu desígnio é aplicá-lo a este assunto em geral - tanto à natural quanto à revelada, tomando por provado que há um autor inteligente para a natureza e governador natural do mundo. Afinal, como não há uma presunção contra isto prévia à sua prova, então se tem provado frequentemente com evidência acumulada, a partir deste argumento advindo da analogia e causas finais, de raciocínios abstratos, da mais antiga tradição e testemunho e do consentimento geral da humanidade. Até onde sei, isto tampouco parece ser negado pela generalidade daqueles que se professam insatisfeitos com a evidência da religião.

Assim como há alguns que, ao invés de atentarem ao que é de fato a constituição da natureza, formam suas noções do governo de Deus sobre hipóteses, há outros que se entregam a especulações vãs e fúteis sobre como o mundo poderia ter sido forjado de modo diferente e, ao imaginarem que as coisas deveriam ter sido dispostas e continuado segundo um modelo melhor do que o que aparece na sua presente disposição e conduta, se baseiam na suposição de que as coisas poderiam ser assim. Suponha-se agora uma pessoa dotada de um tal espírito de modo a ir adiante em seus devaneios até que ela tenha finalmente se fixado sobre algum plano particular da natureza que lhe pareça ser o melhor: Dificilmente deveria ser tido por culpado de alguma detração contra o entendimento humano aquele que dissesse, até de antemão, que o plano fixado por essa pessoa especulativa - mesmo que ela seja a mais sábia entre os filhos dos homens - provavelmente não seria mesmo melhor de acordo com suas próprias noções de melhor, ou que pensou que [o plano] fosse tal que fornecesse ocasiões e motivos para o exercício da maior virtude, ou que fosse produtor da maior felicidade, ou que estes dois fossem necessariamente conectados e se acumulassem num único plano. No entanto, não se pode erroneamente ver de uma vez por todas qual seria o resultado dessas correções e melhorias imaginárias sobre o sistema da natureza ou o quanto elas nos enganariam. E parece que não poderia haver término até que chegássemos a conclusões tais como estas: "todas as criaturas deveriam de primeira ser tão felizes e perfeitas quanto fossem capazes de ser", "nada que seja de risco ou perigo certo lhes deveria ser imposto"; alguns indolentes talvez pensassem que as criaturas não devem fazer absolutamente nada, ou certamente que um cuidado adequado deve ser tomado, ou que elas devessem, (necessariamente ou não, ainda que eventualmente e de fato) fazer sempre o que fosse certo e mais condutor à felicidade, o que se acharia fácil para um poder infinito efetuar ou ao não lhes dar qualquer quaisquer princípios que ameaçariam a feitura dos seus erros ou ao pôr o motivo direto para a ação em cada situação perante suas mentes continuamente e duma maneira tão forte que não falharia em induzir-lhes a agir conforme eles, e que todo método de governo por punições deve ser rejeitado como absurdo, como método circundante canhestro de continuar as coisas, mais ainda, como contrário a um propósito principal para o qual as criaturas supostamente teriam sido feitas, a saber, a felicidade.

Ora, sem considerar o que se deve dizer em particular às várias partes dessa série de loucura e extravagância, o que foi comunicado acima é uma resposta com- 
pleta e direta a tal série, a saber, que podemos ver de antemão que nós não temos faculdades para este tipo de especulação. Afinal, embora se admita que, a partir dos primeiros princípios da nossa natureza, inevitavelmente julgamos ou determinamos serem alguns fins absolutamente preferíveis em si mesmos a alguns outros, e que os fins mencionados agora são (ou, se estes se acumulam num só, que tal único fim é) absolutamente o melhor e, consequentemente, que devemos concluir que o fim último designado na constituição da natureza e conduta da Providência é a maior virtude e felicidade possível, ainda assim estejamos longe de ser capazes de julgar qual disposição particular das coisas seria a mais amigável e auxiliar da virtude ou quais meios devem ser absolutamente necessários para produzir a maior felicidade num sistema de tanta extensão quanto o nosso mundo deve ter, abarcando tudo quanto é passado e o que está por vir, embora devamos supô-lo desprendido de todas as coisas. De fato, estamos tão longe de ser capazes de julgar isto, que não somos juízes para o que podem ser os meios necessários de educar e conduzir uma pessoa rumo à mais alta perfeição e felicidade de sua natureza. Mais ainda, mesmo em pequenos assuntos da vida presente, percebemos que homens de diferentes educações e classes não são juízes competentes da conduta dos outros. Toda a nossa natureza nos leva a atribuir toda a perfeição moral a Deus e negar-Lhe toda imperfeição. E isto será sempre uma prova prática do seu caráter moral, tal como consideramos o que seja uma prova prática, porque é a voz de Deus falando em nós. E disto concluímos que a virtude deve ser a felicidade; e o vício, a miséria de cada criatura; e que regularidade, ordem e retidão não podem senão prevalecer finalmente num universo sob o seu governo. Mas não somos de modo algum juízes de quais sejam os meios necessários para levar a cabo este fim.

Deixe-se então que, ao invés desse vão e não muito inocente emprego de formar modelos imaginários para o mundo, voltemos nossos pensamentos ao que experienciamos ser a conduta da natureza no que diz respeito às criaturas inteligentes - o que deve ser resumido em leis gerais e regras de administração, do mesmo modo que muitas das leis da natureza que dizem respeito à matéria inanimada podem ser coletadas a partir de experimentos. E deixe-se que comparemos a constituição e curso das coisas ao que é dito ser o sistema moral da natureza as dispensações reconhecidas da Providência (i.e., aquele governo sob o qual no encontramos, no qual a religião nos ensina a esperar e acreditar) e ver se são ou não análogos e da mesma qualidade. E com base em tal comparação descobrir-se-á, creio eu, que realmente o são, que ambos podem ser descobertos a partir das mesmas leis gerais e resumidos aos mesmos princípios de conduta divina.

A analogia aqui proposta a ser considerada é duma extensão bem larga, e consiste em várias partes: nalgumas mais exatas e noutras, menos; nalguns poucos exemplos ela talvez chegue a uma prova prática real e noutras, não tanto - ainda assim, nestes há por outros meios uma confirmação do que se prova. Mostrar-se-á inegavelmente o que muitíssimos quiseram mostrar: que o sistema da religião, tanto a natural quanto a revelada, considerado apenas como um sistema e anterior à sua prova não está sujeito ao ridículo, ao menos que a natureza também o esteja. E isto conferirá também uma resposta a quase todas as objeções ao sistema tanto da religião 
natural quanto da revelada, embora talvez não uma resposta num grau tão grande, mesmo que num grau bem considerável, uma resposta às objeções à sua evidência, pois o leitor observará que objeções a uma prova e objeções ao que se diz que se prova são coisas diferentes.

Ora, o governo divino do mundo, que se implica na noção de religião em geral e da cristandade se compreende no seguinte: a humanidade está determinada a viver num estado futuro ${ }^{8}$, neste cada um deverá ser recompensado ou punido ${ }^{9}$ respectivamente por todo aquele comportamento que aqui compreendemos pelas palavras virtuoso ou vicioso e moralmente bom ou mau ${ }^{10}$, nossa vida presente é uma provação, um estado de teste ${ }^{11}$ e de disciplina ${ }^{12}$ para o estado futuro, não obstante as objeções que os homens possam fantasiar a partir de noções de necessidade contra haver tal plano moral como este ${ }^{13}$ e objeções possam parecer se colocar contra sua sabedoria e bondade, pois ele [i.e., o plano] nos é dado a conhecer tão imperfeitamente como agora ${ }^{14}$; sendo este mundo um estado de apostasia e perversidade, e consequentemente de ruína, e sendo o sentido tanto de sua condição quanto seu dever tão grandemente corrompido entre os homens, deu-se ocasião a uma dispensação adicional da Providência da mais alta importância ${ }^{15}$, provada por milagres ${ }^{16}$, mas contendo nisso muitas coisas que nos parecem estranhas e inesperadas ${ }^{17}$, uma dispensação da Providência, que em seu esquema ou sistema de $\operatorname{coisas}^{18}$ continuou pela mediação duma Pessoa divina, o Messias, a fim da recuperação do mundo ${ }^{19}$ ainda não revelada a todos os homens nem provada com a mais forte evidência possível a todos a quem foi revelada, mas apenas para uma parte da humanidade e com uma evidência particular do modo que a sabedoria de Deus pensou ser adequado ${ }^{20}$. Então, o desígnio do seguinte tratado será mostrar que os vários elementos que se objetam principalmente a essa dispensação moral e cristã, incluindo seu esquema, sua publicação e a prova de que Deus nos forneceu sua verdade, que os elementos particulares que se objetam principalmente a toda essa dispensação são análogos ao que se experiencia na constituição e curso da natureza, ou Providência, que as próprias objeções principais, que são supostamente contra a primeira, não são outras que não possam ser de igual justeza contra a última, onde de fato descobriu-se que são inconclusivas, e que este argumento a partir de analogia é em geral irrespondível, indubitavelmente de peso e

\footnotetext{
${ }^{8}$ Cap. I.

${ }^{9}$ Cap. II.

${ }^{10}$ Cap. III.

${ }^{11}$ Cap. IV.

${ }^{12}$ Cap. V.

${ }^{13}$ Cap. VI.

${ }^{14}$ Cap. VII.

${ }^{15}$ Parte II. Cap. I.

${ }^{16}$ Cap. II.

${ }^{17}$ Cap. III.

${ }^{18}$ Cap. IV.

${ }^{19}$ Cap. V.

${ }^{20}$ Cap. VI, VII.
} 
muitíssimo material do lado da religião ${ }^{21}$, não obstante as objeções que podem parecer estar contra ela e o fundamento real que pode haver para a diferença de opinião que ficar sobre ela. Esta é uma descrição geral do que se deve procurar neste tratado. E devo começá-lo com aquilo que é a fundação de todas as nossas esperanças e de todos os nossos medos que são de alguma consideração, digo, a vida futura.

${ }^{21}$ Cap. VIII. 